\title{
Groundwater hydrochemistry of an overexploited aquifer: the case of the Toluca Valley, Mexico
}

\author{
M. C. Jiménez-Moleón, R. M. Fuentes, M. T. Mota-González \\ \& M. Islas-Espinoza \\ Interamerican Center of Water Resources (CIRA), \\ Autonomous University of the State of Mexico (UAEMéx.), Mexico
}

\begin{abstract}
The demographic, industrial and agricultural growth of recent decades in the State of Mexico has caused a considerable increase in groundwater extraction and the overexploitation is mainly due to drinking water, because it is the supply source for the two densely populated zones in the country: the metropolitan areas of Toluca City and Mexico City and its conurbation. In this work, 49 groundwater sources of drinking water were analyzed in two sampling periods (dry and rainy seasons). According to the Electric Conductivity data, $67 \%$ of the samples in the dry and $63 \%$ in the rainy season presented weak mineralization and the rest of the samples showed medium mineralization. In addition, the values of hardness showed that the water had good quality, with the exception of $3 \%$ of the wells in the rainy season, which had medium quality. The corrosion coefficient showed that two samples in the dry season and four in the rainy season had aggressive characteristics that might damage the extraction and distribution networks. The concentrations of major ions (measured by ionic chromatography) in both sampling periods showed this relative abundance: $\mathrm{Na}^{+}>\mathrm{Mg}^{2+}>\mathrm{Ca}^{2+}>\mathrm{K}^{+}=\mathrm{HCO}_{3}>>\mathrm{Cl}^{-}>\mathrm{SO}_{4}{ }^{2-}$. It was found that the $\mathrm{HCO}_{3}{ }^{-}$ concentration increased with the groundwater flow in the area. Moreover, it was also possible to establish the principal species in solution and to corroborate the hydrochemical change in the area of study. Although there continues to be clear predominance of the $\mathrm{Mg}-\mathrm{Na}-\mathrm{HCO}_{3}$ type, the $\mathrm{Na}-\mathrm{HCO}_{3}$ facies showed a progressive increase.
\end{abstract}

Keywords: drinking water, hydrochemistry, major ions, groundwater quality, Toluca Valley, Mexico. 


\section{Introduction}

The alteration of water quality is one of the most worrying problems in the world. At the time when water demands were modest, with limited industrial activity and unsophisticated agriculture, the discharges were not an overly serious problem. While in the current situation, in which the discharges have proliferated in number and pollutant load and various uses have withdrawn significant amounts of water, the problem has grown worse by increasing the number of pollutant sources. An example of the above is the valley of Toluca, fig. 1, an active industrial area with an accelerated urban and industrial growth, which is located in central Mexico, more particularly in the center of the State of Mexico, one of the valleys with greatest elevation in the Mexican highlands. In the 1970 s, the valley had only 13 industries and currently the registered number exceeds 2500 , which has led to overexploitation of their aquifers and pollution of their water bodies by sewage and agricultural runoff. Furthermore, in 1970, 230 wells were drilled to cover the deficiency of water in Mexico City; the subsequent exploitation of aquifers has caused negative effects, such as subsidence, cracking, reduced groundwater levels and hydrological imbalance of the basin.

The Toluca Valley is part of the upper watercourse of the Lerma River, with an average elevation of 2570 meters and a length of nearly $700 \mathrm{~km}^{2}$, is located in

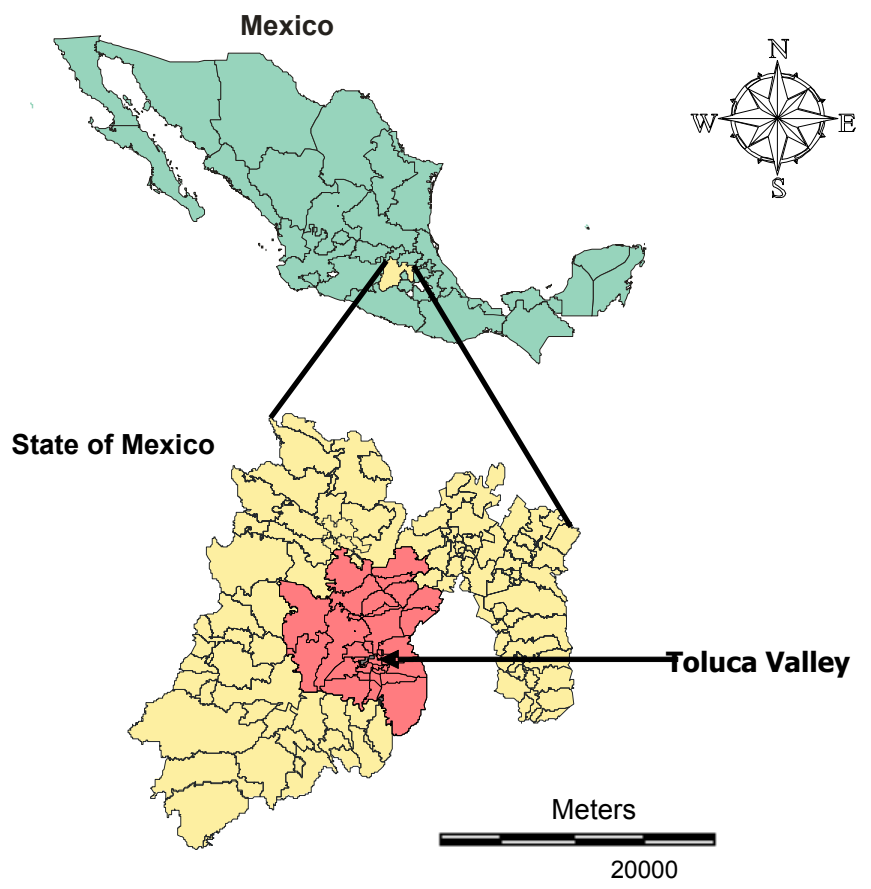

Figure 1: Toluca Valley location. 


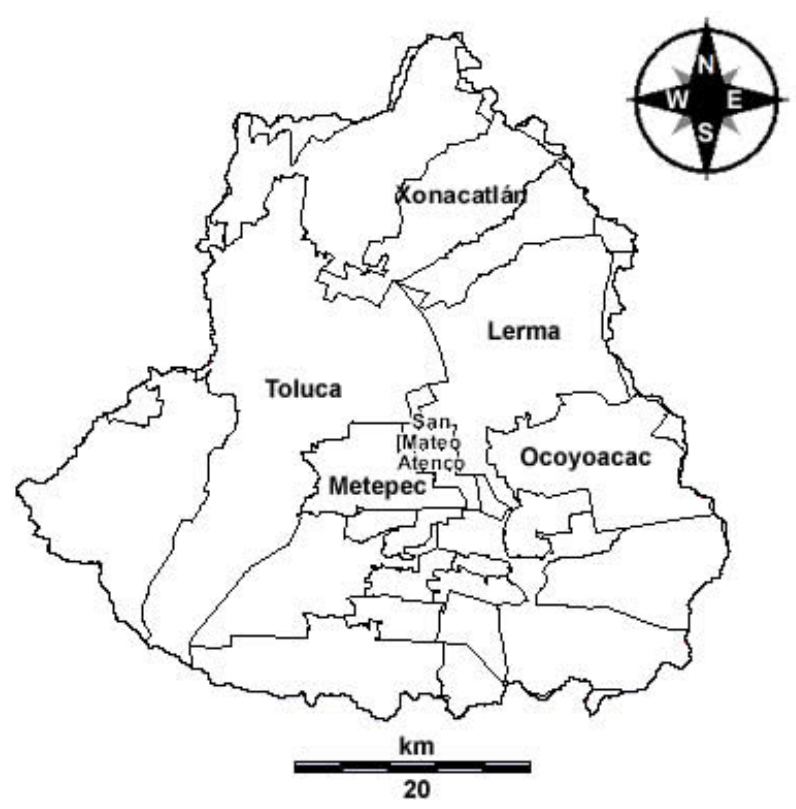

Figure 2: Direction of groundwater flow in the Toluca Valley (adapted from Franco-Plata [1]).

the physiographic province "Eje Neovolcánico Transmexicano", a region consisting of a strip of volcanic calcoalkaline type, whose age corresponds to the Upper Cenozoic. As general characteristics of this province, the presence of basalts with high permeability due to the degree of fracture should be noted. The groundwater flow has a direction similar to the flow of the superficial waters, which tends to move from the mountains surrounding the valley toward the center and north, to be drained into the Valley of Atlacomulco, fig. 2.

Antón [2] reported that the mineralization of the area coincided with what must have been groundwater in a volcanic environment: feldspars contributed with sodium, calcium and potassium, and pyroxene and biotite, with calcium and magnesium. The presence of sulfates and chlorides was low, although on average this was higher, indicating a recharge of surface water caused by rainwater infiltration. The water according to the Piper diagram was similar to that obtained in the campaigns conducted in previous decades regarding $\mathrm{NaHCO}_{3}$ and/or $\mathrm{Mg}\left(\mathrm{HCO}_{3}\right)_{2}$, indicating that the groundwater hydrochemistry in this area had not undergone major changes until then. However, Esteller and Andreu [3] analyzed historical anthropogenic impacts and hydrogeochemical characteristics of the Valley of Toluca aquifer, and concluded that the intense exploitation of this aquifer had caused a change in the groundwater hydrochemistry. In addition to that, initially, the water extracted from the aquifer was linked to a local flow (recharge by rainwater and by lateral feeding from other aquifers), but, by 1998, the hydrochemistry became characteristic of a regional flow, as evidenced by the increase (from $26 \%$ to $35 \%$ ) of the $\mathrm{Na}-\mathrm{HCO}_{3}$ type. 


\section{Materials and methods}

Two samplings were performed, one between the months of May and June 2005 (dry) and one more in October and November of that year (rainy), to assess the possible seasonal influence on the water quality in the study area. Forty nine sampling points were considered in the municipalities of Xonacatlan, Lerma, San Mateo Atenco, Metepec and Toluca, the area most affected by anthropogenic activity in the Valley of Toluca, fig. 2. Sampling, preservation and transportation were made according to criteria established by the APHA-AWWA-WFPC [4]. In addition, for each of the samples the following were determined in situ: $\mathrm{pH}$, temperature (T) and electrical conductivity (EC) with a multielectrode Conductronic PC18 portable. Major ions were analyzed by HPLC.

\section{Results and discussion}

The overall results obtained during the sampling program parameters in situ were (dry-rainy): $\mathrm{T}=19.9 \pm 0.2^{\circ} \mathrm{C}-18.4 \pm 0.1^{\circ} \mathrm{C} ; \mathrm{pH}=7.12 \pm 0.02-7.60 \pm 0.01$ and $\mathrm{EC}=$ $299 \pm 163 \mathrm{microS} / \mathrm{cm}-311 \pm 157 \mathrm{microS} / \mathrm{cm}$. So it was concluded that seasonal variation was not significant, only in the case of EC was the spatial variation significant, tending to increase towards the central part of the area of study. It means that it is parallel to the groundwater flow, indicating that mineralization increases with the contact time in the aquifer. An individual analysis of the wells determined that the wells that were subject to greater exploitation also have a higher degree of mineralization.

The degree of mineralization was determined according to [5], obtaining that in the dry period, $10 \%$ of the wells showed a weak mineralization, $57 \%$ medium accentuated mineralization and 33\% medium mineralization, while in the rainy season the range of conductivity values narrowed, but increased the mineralization, since $12 \%$ of samples showed weak mineralization, $51 \%$ medium accentuated mineralization and the rest were medium.

The concentrations of the major anions and their relationship to each other can be seen in fig. 3 , while table 1 shows the minimum, maximum and average values of both sampling periods. The average of all these anions hardly varies seasonally, following the order: $\mathrm{HCO}_{3}{ }^{-}>>\mathrm{Cl}^{-}>\mathrm{SO}_{4}{ }^{2-}$. However, reviewing the limits of the range of variation, it can be seen that while the bicarbonate ion tended to increase in the rainy season, the sulfate ion was concentrated during the dry season. The ranges of variation of the most abundant anions, and their averages, are consistent with those reported in previous studies by CONAGUA, the National Water Commission [6].

Table 1: Minimum, maximum and average values of the major anions in the Toluca Valley wells.

\begin{tabular}{|c|c|c|c|c|c|c|}
\hline \multirow{2}{*}{$\begin{array}{c}\text { Concentration } \\
(\mathrm{mg} / \mathrm{L})\end{array}$} & \multicolumn{2}{|c|}{ Minimum } & \multicolumn{2}{c|}{ Maximum } & \multicolumn{2}{c|}{ Average } \\
\cline { 2 - 7 } & Dry & Rainy & Dry & Rainy & Dry & Rain \\
\hline $\mathrm{HCO}_{3}{ }^{-}$ & 49.67 & 70.87 & 241.6 & 257.2 & $138 \pm 34$ & $140 \pm 44$ \\
\hline $\mathrm{Cl}^{-}$ & 7.66 & 6.93 & 32.27 & 23.71 & $14.17 \pm 0.38$ & $12.80 \pm 0.24$ \\
\hline $\mathrm{SO}_{4}{ }^{2-}$ & 0.84 & 1.04 & 12.28 & 12.41 & $4.52 \pm 0.19$ & $4.00 \pm 0.10$ \\
\hline
\end{tabular}




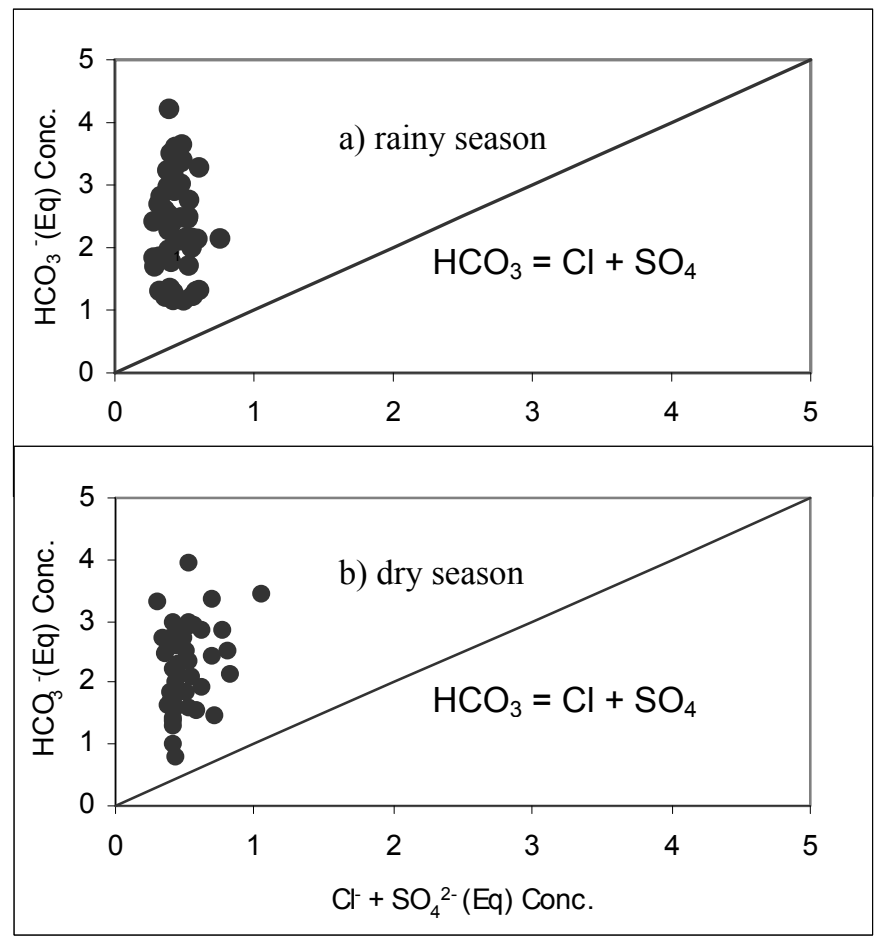

Figure 3: $\quad$ Relation $\mathrm{HCO}_{3}{ }^{-}$versus $\mathrm{Cl}^{-}+\mathrm{SO}_{4}{ }^{2-}$.

In fig. 3, as described by the data in table 1, in both sampling periods a single group was identified in the groundwater of the Valley of Toluca, which clearly had the bicarbonate ion as predominant. Thus, the low presence of sulfate and chloride in the Toluca Valley wells is logical, because the soil in the area contains these ions in small quantities. In fig. 3 it also can be seen that while the sum of the concentrations of $\mathrm{Cl}^{-}$and $\mathrm{SO}_{4}{ }^{2-}$ showed a little spatial variation, the $\mathrm{HCO}_{3}{ }^{-}$concentration increased considerably from one well to another. Given the location of the wells, the low content of bicarbonate found in the eastern zone (Municipality of Ocoyoacac), i.e., in the areas closest to the recharge zones, and that the content of $\mathrm{HCO}_{3}^{-}$increased parallel to the groundwater flow is remarkable. Therefore, the increase in the residence in the aquifer determined that water could dissolve more and thus, increase its content of $\mathrm{HCO}_{3}{ }^{-}$.

Furthermore, it is noteworthy that according to results of the groundwater balance presented by [7], the natural vertical recharge in the valley of Toluca has been increasing year by year: by $21 \%$ during $1992-1996$, and by $81 \%$ during 1996-2000. While the recharge from the mountains (Nevado de Toluca and Sierra de las Cruces) increased by just $0.11 \%$ in 2000 , i.e., by 2000 , the vertical natural recharge in the center of the Valley was $12 \%$ higher than the recharge in the mountains. This effect might be associated with the increase in bicarbonate 
Table 2: $\quad$ Concentration $(\mathrm{mg} / \mathrm{L})$ of major cations in Toluca Valley wells.

\begin{tabular}{|c|c|c|c|c|c|c|c|c|}
\hline \multirow[t]{2}{*}{ Well } & \multicolumn{4}{|c|}{ Dry } & \multicolumn{4}{|c|}{ Rainy } \\
\hline & $\mathrm{Na}$ & $\mathrm{K}$ & $\mathrm{Mg}$ & $\mathrm{Ca}$ & $\mathrm{Na}$ & $\mathrm{K}$ & $\mathrm{Mg}$ & $\mathrm{Ca}$ \\
\hline 1 & 20.80 & 2.78 & 14.51 & 12.16 & 22.28 & 3.25 & 14.91 & 14.82 \\
\hline 2 & 23.25 & 3.20 & 18.25 & 13.24 & 23.60 & 2.87 & 18.07 & 12.74 \\
\hline 3 & 17.55 & 3.21 & 14.17 & 11.59 & 20.45 & 4.72 & 19.72 & 18.65 \\
\hline 4 & 17.69 & 4.81 & 20.34 & 19.30 & 21.19 & 5.24 & 21.49 & 20.80 \\
\hline 5 & 19.74 & 4.19 & 16.76 & 16.30 & 20.13 & 4.34 & 17.37 & 17.21 \\
\hline 6 & 15.79 & 3.24 & 11.77 & 11.70 & 14.19 & 3.34 & 11.02 & 11.29 \\
\hline 7 & 19.94 & 2.94 & 13.78 & 13.36 & 20.34 & 2.49 & 13.79 & 11.82 \\
\hline 8 & 15.21 & 3.37 & 11.70 & 11.61 & 15.33 & 3.21 & 11.11 & 11.20 \\
\hline 9 & 20.72 & 3.87 & 11.15 & 12.81 & 19.40 & 2.58 & 14.06 & 11.85 \\
\hline 10 & 21.97 & 4.82 & 13.42 & 14.27 & 20.27 & 4.52 & 14.63 & 14.98 \\
\hline 11 & 19.82 & 2.17 & 11.80 & 10.67 & 19.83 & 1.51 & 12.72 & 10.88 \\
\hline 12 & 14.73 & 2.21 & 10.76 & 9.11 & 16.35 & 2.33 & 11.14 & 9.61 \\
\hline 13 & 16.15 & 3.76 & 13.21 & 13.27 & 16.75 & 3.88 & 15.67 & 14.22 \\
\hline 14 & 14.68 & 3.46 & 10.18 & 10.20 & 15.71 & 4.53 & 10.13 & 11.20 \\
\hline 15 & 14.22 & 2.02 & 8.29 & 9.15 & 14.78 & 1.74 & 8.40 & 9.32 \\
\hline 16 & 30.32 & 2.58 & 21.81 & 16.10 & 32.87 & 2.72 & 22.94 & 21.26 \\
\hline 17 & 21.25 & 2.15 & 12.85 & 10.74 & 20.46 & 1.90 & 13.26 & 11.29 \\
\hline 18 & 21.22 & 2.23 & 14.40 & 12.77 & 19.67 & 1.87 & 13.16 & 11.92 \\
\hline 19 & 26.92 & 2.15 & 17.41 & 13.47 & 26.35 & 1.77 & 17.56 & 13.22 \\
\hline 20 & 22.27 & 3.93 & 15.87 & 11.29 & 24.58 & 3.95 & 13.84 & 10.20 \\
\hline 21 & 15.23 & 2.36 & 9.62 & 11.06 & 16.17 & 3.29 & 9.93 & 10.53 \\
\hline 22 & 46.72 & 6.68 & 8.94 & 11.97 & 49.90 & 4.89 & 9.22 & 12.26 \\
\hline 23 & 24.57 & 3.62 & 9.72 & 13.32 & 24.39 & 4.26 & 11.38 & 15.32 \\
\hline 24 & 22.78 & 4.83 & 6.94 & $\begin{array}{l}8.88 \\
\end{array}$ & 17.61 & 2.64 & 10.24 & 12.72 \\
\hline 25 & 16.36 & 3.38 & 8.65 & 9.91 & 17.23 & 2.74 & 9.82 & 12.45 \\
\hline 26 & 27.62 & 3.66 & 15.12 & 14.35 & 27.69 & 3.77 & 15.34 & 14.17 \\
\hline 27 & 28.22 & 2.62 & 12.39 & 14.14 & 28.89 & 2.97 & 12.46 & 13.73 \\
\hline 28 & 24.39 & 2.65 & 11.25 & 11.90 & 19.14 & 2.63 & 11.84 & 12.13 \\
\hline 29 & 18.91 & 2.08 & 11.36 & 10.52 & 19.74 & 1.91 & 11.86 & 10.70 \\
\hline 30 & 18.33 & 2.12 & 10.94 & 10.43 & 18.38 & 2.27 & 10.78 & 10.87 \\
\hline 31 & 21.69 & 3.21 & 10.34 & 10.29 & 18.35 & 3.56 & 15.90 & 15.28 \\
\hline 32 & 21.34 & 1.88 & 12.78 & 11.82 & 19.38 & 1.44 & 11.20 & 10.77 \\
\hline 33 & 19.85 & 3.27 & 18.85 & 17.51 & 27.32 & 4.57 & 31.44 & 27.26 \\
\hline 34 & 26.85 & 2.55 & 10.79 & 11.19 & 21.78 & 2.83 & 13.12 & 13.25 \\
\hline 35 & 19.35 & 3.65 & 15.04 & 14.97 & 20.05 & 3.72 & 16.26 & 15.59 \\
\hline 36 & 19.45 & 3.14 & 8.20 & 8.62 & 19.77 & 2.81 & 13.20 & 14.90 \\
\hline 37 & 18.74 & 2.80 & 12.62 & 14.18 & 19.19 & 2.73 & 13.19 & 14.90 \\
\hline 38 & 33.67 & 6.64 & 15.34 & 18.87 & 19.97 & 2.84 & 13.11 & 14.97 \\
\hline 39 & 15.28 & 3.93 & 7.28 & 9.75 & 14.70 & 3.68 & 6.27 & 7.80 \\
\hline 40 & 11.64 & 3.32 & 5.92 & 8.70 & 14.36 & 3.52 & 5.92 & 7.54 \\
\hline 41 & 16.16 & 2.56 & 10.22 & 10.92 & 14.69 & 1.48 & 10.75 & 9.33 \\
\hline 42 & 13.87 & 1.44 & 10.57 & 9.74 & 13.96 & 1.31 & 11.14 & 9.73 \\
\hline 43 & 16.63 & 1.19 & 10.76 & 10.22 & 17.64 & 0.84 & 11.82 & 9.92 \\
\hline 44 & 22.90 & 1.53 & 8.05 & 8.81 & 24.89 & 1.56 & 7.96 & 8.93 \\
\hline 45 & 18.25 & 2.06 & 13.59 & 11.17 & 27.36 & 3.58 & 17.24 & 15.27 \\
\hline 46 & 16.61 & 1.65 & 13.10 & 10.89 & 19.37 & 5.60 & 11.83 & 9.52 \\
\hline 47 & 18.09 & 0.92 & 11.59 & 9.34 & 19.26 & 0.87 & 11.57 & 9.28 \\
\hline 48 & 18.33 & 0.83 & 11.19 & 9.20 & 18.26 & 3.54 & 9.50 & 13.62 \\
\hline 49 & 18.76 & 3.38 & 13.91 & 12.07 & 18.34 & 3.65 & 9.23 & 11.98 \\
\hline
\end{tabular}


concentrations observed in $49 \%$ of the sources of supply during the rainy season. However, it must be noted that the $51 \%$ of the remaining sources of supply evidenced a dilution phenomenon as an effect of the rainfall, which made them sources of a potential risk of contamination.

Subsequently, the water tendency to corrosion was determined with the Larson index, $\mathrm{k},[8,9]: \mathrm{k}=\left(2\left[\mathrm{SO}_{4}{ }^{2-}\right]+\left[\mathrm{Cl}^{-}\right]\right) /\left[\mathrm{HCO}_{3}{ }^{-}\right]$. According to [8], a $\mathrm{k}$-value $\leq 0.25$ indicates resistance to corrosion, while higher values are generally more corrosive and can damage the water supply systems. The $\mathrm{k}$ obtained data indicated that 2/49 wells in the dry season and 4/49 in the rainy season showed aggressive characteristics.

Table 2 shows the concentrations obtained from the major cationic constituents quantified in the sources of supply in the Toluca Valley area during both sampling periods.

Once the concentrations of the major components in both sampling periods were obtained, the ionic balance was made to all the points under analysis, finding that the error was always less than $5 \%$.

The average values of $\mathrm{Ca}^{2+}$ in the dry and rainy seasons were $11.99 \mathrm{mg} / \mathrm{L}$ and $12.92 \mathrm{mg} / \mathrm{L}$, respectively. Spatially analyzing the data, it was observed that $\mathrm{Ca}^{2+}$ concentration increased towards the central part of the study area. The $\mathrm{Mg}^{2+}$ values were slightly higher than those of $\mathrm{Ca}^{2+}$ : with averages of $12.39 \mathrm{mg} / \mathrm{L}$, in the dry season, and $13.23 \mathrm{mg} / \mathrm{L}$ in the rainy season, following a spatial distribution very similar to $\mathrm{Ca}^{2+}$. Sodium, with average concentrations of $20.50 \mathrm{mg} / \mathrm{L}$ and $20.65 \mathrm{mg} / \mathrm{L}$ in the dry and rainy season, respectively, became the main cation; while the average concentrations of $\mathrm{K}^{+}$in the dry and rainy seasons were $3.0 \mathrm{mg} / \mathrm{L}$ and $3.02 \mathrm{mg} / \mathrm{L}$, respectively, confirming (as expected) the conservative value of these parameters.

From the values obtained in this study, it could be concluded that the hydrogeochemical feature of the water in the area of study is the predominance of bicarbonate and sodium ions, which is consistent with other studies in the Toluca Valley $[3,6,10,11]$. The relative abundances of the major ions in water were found in the following order: $\mathrm{Na}^{+}>\mathrm{Mg}^{2+}>\mathrm{Ca}^{2+}>\mathrm{K}^{+}=\mathrm{HCO}_{3}^{-}>>\mathrm{Cl}^{-}>\mathrm{SO}_{4}{ }^{2-}$.

The total hardness $(\mathrm{TH})$ was determined by stoichiometric calculations from the concentrations of calcium and magnesium, so the quality of the water in the study area could be classified [5] as very good in the dry season (100\% of well samples with values of $\mathrm{TH}<122 \mathrm{mg} \mathrm{CaCO}_{3} / \mathrm{L}$ ), while in the rainy season, $98 \%$ of the samples had between 43 and $48 \mathrm{mg} \mathrm{CaCO}_{3} / \mathrm{L}$ (good quality) and 2\% had a value of $199 \mathrm{mg} \mathrm{CaCO}_{3} / \mathrm{L}$ (medium quality).

The graphical treatment of major ion chemistry [12] was analyzed. Thus, the affinity of $\mathrm{Na}^{+}+\mathrm{K}^{+}$versus $\mathrm{Cl}^{-}$was studied, plotting their equivalent concentrations, because the $\mathrm{Cl}^{-}$ion tends normally to be associated more with alkali metals than with $\mathrm{Ca}^{2+}$ and $\mathrm{Mg}^{2+}$. In fig. 4, it is deduced that $\mathrm{Na}^{+}$and $\mathrm{K}^{+}$ might be related to $\mathrm{Cl}^{-}$ions and there could be an excess available to join other anions. Fig. 4 corresponds to the rainy season, but the same trend was observed in the dry season. In addition, the natural affinity of the relation between $\mathrm{Ca}^{2+}+$ $\mathrm{Mg}^{2+}$ and $\mathrm{HCO}_{3}{ }^{-}$was graphically evaluated, fig. 5, where it is shown that in most cases, even after forming the aqueous species $\mathrm{Ca}-\mathrm{HCO}_{3}$ and $\mathrm{Mg}-\mathrm{HCO}_{3}$, there 
was an excess of $\mathrm{HCO}_{3}{ }^{-}$that could be related to other relatively abundant ions $\left(\mathrm{Na}^{+}\right.$and $\left.\mathrm{K}^{+}\right)$. Fig. 5 corresponds to the dry season; however, the same trend occurred in the rainy season. In conclusion, the relationships found by considering the affinity among ions (figs. 4 and 5), the aqueous species $\mathrm{Na}-$ $\mathrm{HCO}_{3}, \mathrm{Ca}-\mathrm{HCO}_{3}, \mathrm{Mg}-\mathrm{HCO}_{3}, \mathrm{Na}-\mathrm{Cl}$ and $\mathrm{K}-\mathrm{Cl}$, were likely to occur in the Toluca Valley groundwater system.

Finally, the geochemistry of water was analyzed through the Piper trilinear diagram (fig. 6); the presented figure corresponds to the rainy season, although the trend is the same in both sampling periods. The samples were mainly of the $\mathrm{NaMg}-\mathrm{HCO}_{3}$ type, but also defined were $\mathrm{MgNa}-\mathrm{HCO}_{3}$ and $\mathrm{MgCa}-\mathrm{HCO}_{3}$, indicative of a volcanic environment. Given the location of the wells, in the north and northeast of the area (Lerma, Ocoyoacac and Xonacatlan), the water mostly belonged to the $\mathrm{Na}-\mathrm{HCO}_{3}$ family, while in the south and southwest, the Mg$\mathrm{HCO}_{3}$ and $\mathrm{Ca}-\mathrm{HCO}_{3}$ facies were observed. With respect to cations, the water was classified as mixed, while for anions, the water was totally bicarbonated.

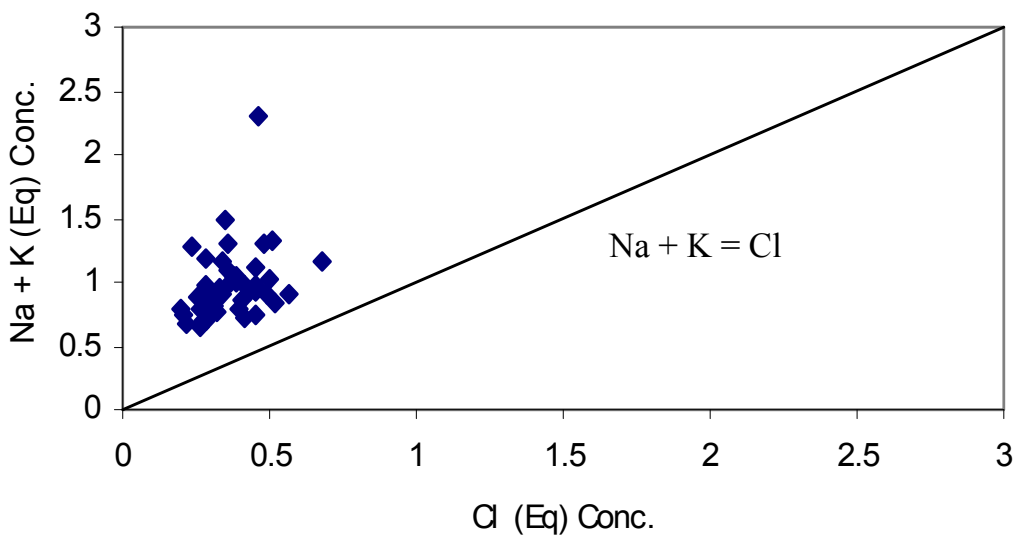

Figure 4: $\quad$ Relation alkali versus $\mathrm{Cl}^{-}$(rainy season).

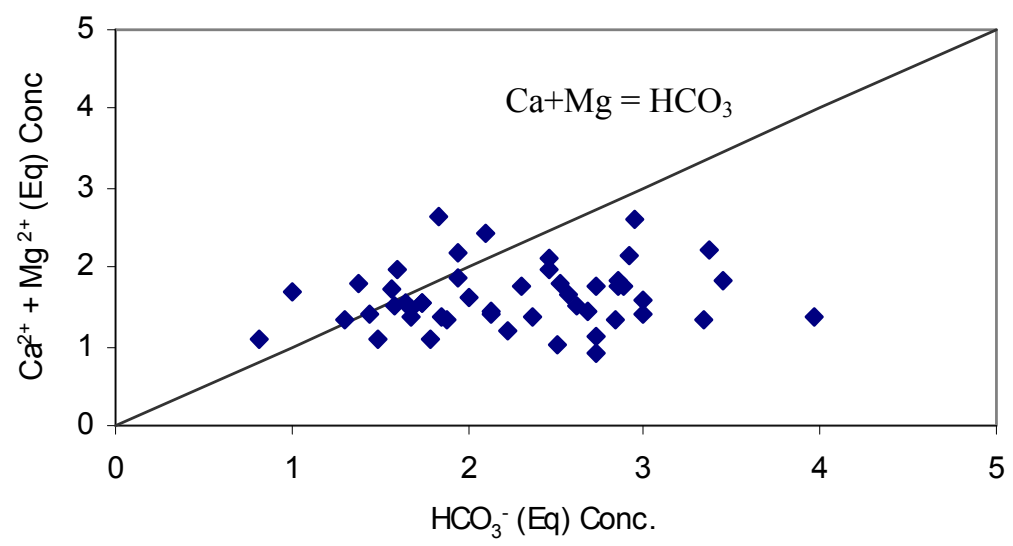

Figure 5: $\quad \mathrm{Ca}^{2+}+\mathrm{Mg}^{2+}$ versus $\mathrm{HCO}_{3}{ }^{-}$(dry season). 


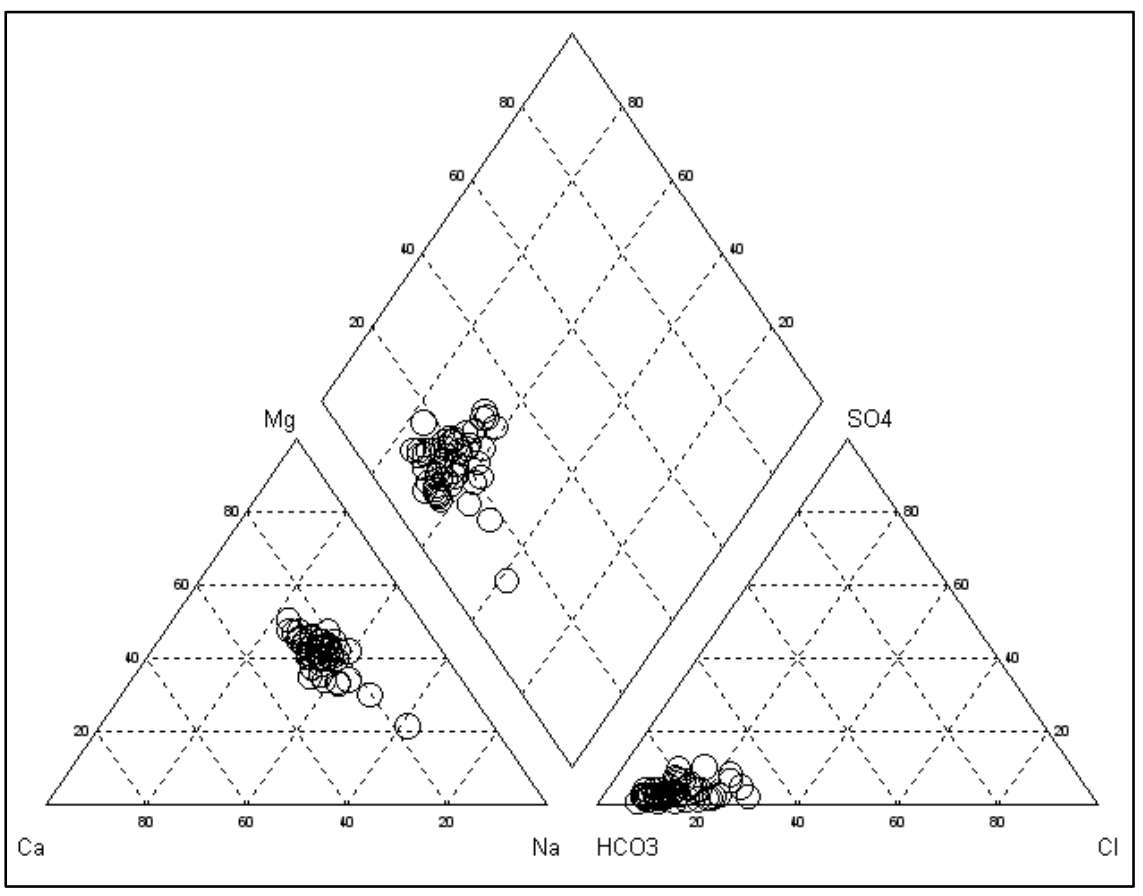

Figure 6: $\quad$ Piper diagram for the Toluca Valley wells (rainy season).

Historically, the researches on the area of study concluded that the hydrochemical facies of the Toluca Valley would not have presented changes until $1986\left(\mathrm{MgNa}-\mathrm{HCO}_{3}, \mathrm{NaMg}-\mathrm{HCO}_{3}\right)$ [7]; however, by 1998 a change in the hydrochemistry was reported, which began to show an increase in the $\mathrm{Na}-\mathrm{HCO}_{3}$ facie, reaching 38\% [3]. This trend was confirmed and accentuated in the present study, where this facie reached $47 \%$ of the samples. The progressive increase of the sodium cation in the water is probably due to the dominating soil type in the area (rhyolites and trachytes) and to the overexploitation that has been exerted on the resource.

\section{Conclusions}

After treatment and analysis of results, the following conclusions were reached.

The physicochemical parameters, $\mathrm{T}, \mathrm{pH}$ and $\mathrm{EC}$ showed no great seasonal variation, although in the case of EC, the range of spatial variation is quite large. According to EC, the $33 \%$ and $37 \%$ of the samples in the dry and rainy seasons, respectively, showed marked mineralization.

The chemical composition of water did not show a significant seasonal change. The relative abundance of ions was: $\mathrm{Na}^{+}>\mathrm{Mg}^{2+}>\mathrm{Ca}^{2+}>\mathrm{K}^{+}=\mathrm{HCO}_{3}>>\mathrm{Cl}^{-}$ $>\mathrm{SO}_{4}{ }^{2-}$. In addition, it was found that the main anion concentration $\left(\mathrm{HCO}_{3}{ }^{-}\right)$ 
increased in parallel to groundwater flow, i.e., when the residence time of water in the aquifer was greater.

With regard to the total hardness, the water had good quality, except for $3 \%$ of the wells in the rainy season that had an average quality.

The coefficient of corrosion $(\mathrm{k})$ showed that two samples in the dry season and four in the rainy season showed aggressive characteristics that could damage the extraction and distribution network.

Chemical affinity studies identified that the more likely species in solution were $\mathrm{NaHCO}_{3}, \mathrm{Ca}\left(\mathrm{HCO}_{3}\right)_{2}, \mathrm{Mg}\left(\mathrm{HCO}_{3}\right)_{2}, \mathrm{NaCl}$ and $\mathrm{KCl}$.

The hydrochemical classification of the water through the Piper diagram showed a clear predominance of the $\mathrm{MgNa}-\mathrm{HCO}_{3}$ facies. In addition, the hydrochemical change in the drinking water sources due to the gradual increase in the $\mathrm{Na}-\mathrm{HCO}_{3}$ type was confirmed.

\section{Acknowledgement}

This publication was made possible thanks to the financial support of the Autonomous University of the State of Mexico, through the Secretary of Research and Advanced Studies, Projects 2005/2005 and 2506/2007U.

\section{References}

[1] Franco-Plata, R. Adecuación del método de evaluación de vulnerabilidad de acuíferos (DRASTIC), mediante el uso del trazador de partículas en el acuífero del curso alto del río Lerma, Estado de México, M. Sc. Thesis CIRA-UAEMéx., 2002.

[2] Antón, D., Las aguas subterráneas (Chapter 6). Sequía en un mundo de agua, ed. Piriguazú Ediciones/CIRA-UAEMéx.: San José/Toluca, pp.67100, 2000.

[3] Esteller, M.V. \& Andreu, J.M., Anthropic effects on hydrochemical characteristics of the Valle de Toluca aquifer (Central Mexico). Hydrogeology Journal, 13(2), pp.378-390, 2005

[4] APHA-AWWA-WFPC, Standard Methods for Examination of Water and Wastewater, 17th edition, American Public Health Association \& Water Pollution Control Federation: Washington, 1992.

[5] Rodier, J., Análisis de aguas. Aguas naturales, aguas residuales, agua de mar, Omega S.A.: Barcelona, 1998.

[6] CONAGUA, Programa Hidráulico Nacional, Comisión Nacional del Agua: México D.F., 1998.

[7] CONAGUA, Determinación de la disponibilidad de agua en el acuífero Valle de Toluca, Comisión Nacional del Agua: México D.F., 2002.

[8] Özcan, H., Hüseuin, E., Alper, B., Yasemin, K., Orhan, Y. \& Yiğini, Y., Assessment of the water quality of Troia for the multipurpose usages. Environmental Monitoring and Assessment, 130(1-3), 389-402, 2007. 
[9] Zhang, Y. \& Edwards, M., Anticipating effects of water quality changes on iron corrosion and red water, Journal of Water Supply: Research and Technology-AQUA, 56(1), 55-68, 2007

[10] Esteller, M.V. \& Díaz-Delgado, C., Environmental effects of aquifer overexploitation: A case study in highlands of Mexico. Environmental Management, 29(2), 266-278, 2002.

[11] Espinoza, R. Relación entre factores antrópicos y naturales y la concentración de nitrato en agua subterránea del valle de Toluca. M. Sc. Thesis, Faculty of Chemistry-UAEMéx., 2005.

[12] Umar, R., Muqtada, M., Khan, A. \& Absar, A., Groundwater hydrochemistry of a sugarcane cultivation Belt in parts of Muzaffarnagar district, Uttar Pradesh, India, Environmental Geology, 49(7), 999-1008, 2006 . 